\title{
Market chain analysis of baobab (Adansonia digitata L.) and tamarind (Tamarindus indica L.) products in Mali and Benin
}

\author{
Emmy De Caluwé \\ Supervisor: Patrick Van Damme \\ Department of Plant Production, Ghent University
}

Public defence: 5 May 2011

Global food security and economic growth depend on a declining number of plant species. This has placed the future supply of food and rural incomes at risk. Recently, there has been an increasing interest in underutilised species as they allow to improve the livelihoods of the rural poor by generating income, supporting food security and improving nutrition.

Mali and Benin are both characterised by high rates of rural poverty, low basic health services, problematic and unstable food security, and unsustainable use of natural resources. In addition, rural and urban people remain very dependent on the multiple goods and services supplied by indigenous trees and woody plants. Any attempt to find sustainable solutions to the problems listed for Mali and Benin should take into account locally known, used and available natural resources.

In West Africa, baobab (Adansonia digitata L.) and tamarind (Tamarindus indica L.) form part and parcel of traditional farming systems or agroforestry parklands, and both species have been identified by local people as priority species to domesticate. Notwithstanding the great agronomic, ecological, nutritional, cultural and economic importance of baobab and tamarind products, very little information is available on the basic market functioning and structures, such as stakeholders involved, trade channels and/or patterns of value adding along the market chain. The present $\mathrm{PhD}$ thesis thus is the first study that attempts to fill this information gap.

The overall objective of the research presented here is to obtain insight in the structure and functioning of the markets of baobab and tamarind products in Mali and Benin. To achieve this goal, the following specific research objectives are set: (i) identify all chain actors involved in the market(s) of baobab and tamarind products in Mali and Benin, and describe their characteristics, activities and linkages; (ii) map the market(s) of baobab and tamarind products in Mali and Benin; (iii) analyse the market chain of baobab and tamarind products in Mali and Benin; and (iv) formulate possible scenarios on how to add more value to baobab and tamarind products in Mali and Benin, and how to better organise their market chains.

To formulate an answer to the objectives set for the present study, an in-depth analysis of the market chain for selected baobab and tamarind products is required. During field research, in total, 507 individual stakeholders in the market chain of baobab and tamarind products were interviewed in Mali between July and October 2007, whereas in Benin we interviewed 221 informants during the period January - April 2010. 
Gatherers of baobab and tamarind products are categorised as smallholders. After harvesting, they transform fresh baobab leaves into dry baobab leaves and/or baobab leaf powder, baobab fruits are processed into baobab fruit pulp, tamarind leaves are dried, and tamarind fruit pods are stripped from their shell. In the present study, the portion of cash income obtained from baobab and tamarind products is about $4 \%$ for the poorest and $5 \%$ for the richer households in Mali, whereas, in Benin, a contribution of up to $\mathrm{II} \%$ is reported for the poorest group of smallholders. These figures show that baobab and tamarind products fall into the gap-filling income category. The majority of surveyed gatherers in Mali and Benin reported to sell their baobab and tamarind products at the farmgate. Baobab and tamarind fruits and leaves are harvested using traditional harvesting techniques, which only require manual labour and low-cost tools. Leaf harvesting practices, in the case of baobab, may negatively impact on fruit production. Therefore, in general, sustainable harvesting practices need to be developed and proposed to promote the species' conservation and avoid overexploitation. Surveyed gatherers in Mali and Benin mentioned dangerous harvesting techniques, seasonality and limited availability of baobab and tamarind products, time-consuming processing practices, product quality and a lack of market information as their major problems.

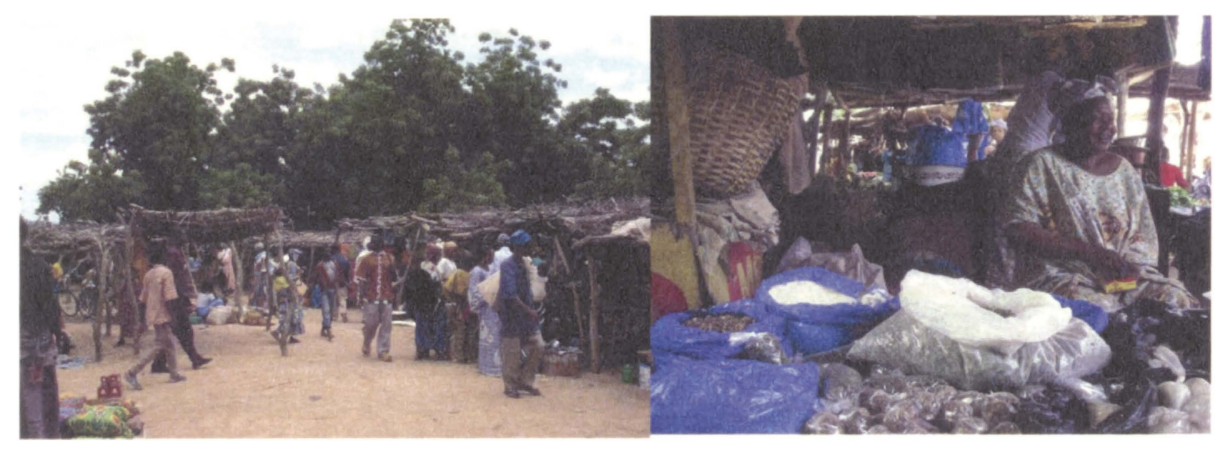

Local market (left) and petty trader (right) of baobab and tamarind products in Mali.

Traders of baobab and tamarind products are mainly women. They fulfil different and varying functions, which points to a lack of functional specialisation. Findings in the present study revealed three possible price setting processes: (i) fair negotiation, usually when the produce is sold at the market place; (ii) traders have more bargaining power, especially when the produce is sold at the farmgate; and (iii) collecting gatherers in $\mathrm{Be}-$ nin have more influence in the price setting than traders. The latter shows the beneficial impact of collective action strategies in increasing the bargaining power of smallholders. Additionally, the present study identified distinct trade centres for baobab leaf powder, baobab fruit pulp and tamarind fruit pods in Mali and Benin. The surveyed traders reported the following principal problems: variable product quality, limited storage space, transport difficulties due to poor roads, lack of market information and no access to formal financial services. 


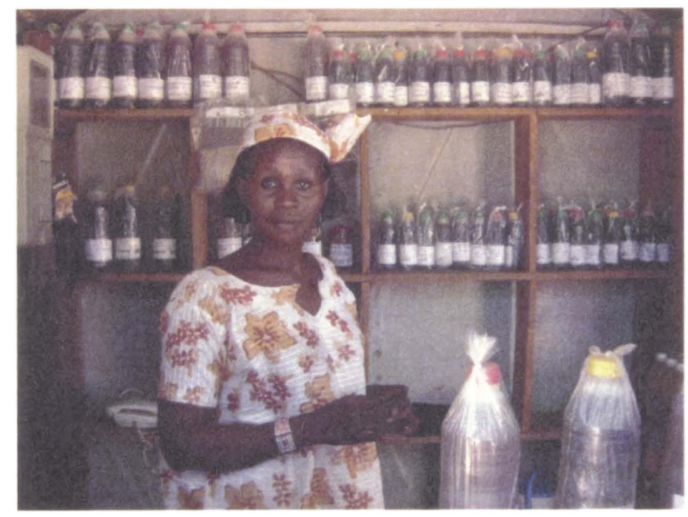

Processor of baobab and tamarind products in Mali.

Processors in Benin reported to make juice from baobab and tamarind fruit pulp, whereas in Mali, processors use baobab and tamarind fruits in the preparation of juice, syrup, jam and instant juice powder. Additionally, baobab fruit pulp is used in Mali for mixing with millet flour to prepare millet cream (locally called dégué). Processing is generally not reported as a one-man's business and processing (family) enterprises were found to transform a whole range of different products. Notwithstanding manual processing techniques and simplicity of equipment used, the portion of efficient processors identified by means of a data envelopment analysis is $63 \%$ in Mali and $49 \%$ in Benin. Thus, processors appear to be efficient under the given circumstances in Mali and Benin. The major cost that processors in both countries face is the cost of packaging material. Moreover, surveyed processors in Mali and Benin reported inappropriate and expensive packaging material, limited availability of adequate processing equipment, bad transport due to poor road infrastructure, lack of financial means and limited market information as main constraints.

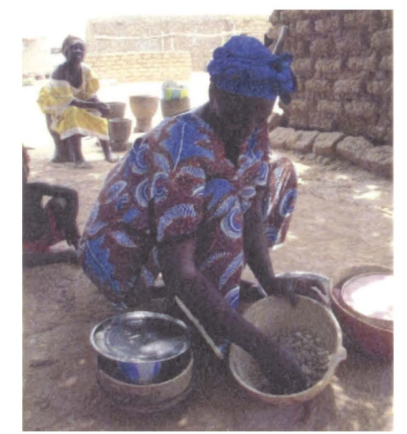

Rural consumer of baobab fruit pulp in Mali. 
Both rural and urban consumers buy and use baobab and tamarind products on a regular basis. Baobab fruit pulp is reported to be used in porridges and/or juices, whereas baobab leaves are used in sauce preparations. Most surveyed consumers use tamarind leaves and fruits in the preparation of juices and/or for souring meals. Substitution products for all baobab and tamarind products are reported in the present study and confirmed by literature. The main problems recorded by consumers are seasonality of supply, price fluctuations and unreliable product quality.

In total, six different baobab and tamarind products are reported in this study to be traded in Mali and Benin. Based on the market maps drawn for these products, three different market chains were identified: (i) market chain of fresh baobab leaves and tamarind leaves, characterised as locally important with a domestic potential; (ii) market chain of dry baobab leaves and baobab leaf powder, characterised as important on domestic level with a regional potential; and (iii) market chain of baobab and tamarind fruits, characterised by its domestic and regional importance with international potential.

The present study is the first that has recorded quantities bought and sold, and purchasing and selling prices for different actors involved in the commercialisation of baobab and tamarind products in Mali and Benin. Based on the quantities and prices recorded, baobab fruit pulp is traded in larger quantities in Benin than in Mali, whereas baobab leaf powder and tamarind fruit pods are marketed in larger quantities in Mali than in Benin. Prices are lower in Benin for baobab fruit pulp and baobab leaf powder than in Mali, while tamarind fruit pods are cheaper in Mali when compared to Benin. Moreover, commercialisation of baobab and tamarind products was evidenced to create a lot of employment opportunities. In addition, we calculated added values for baobab and tamarind products and showed that processors and gatherers tend to have the highest added values. This trend is found to be more pronounced in Mali than in Benin. As added value does not take into account any costs, it is impossible to prove which actor has the highest margins.

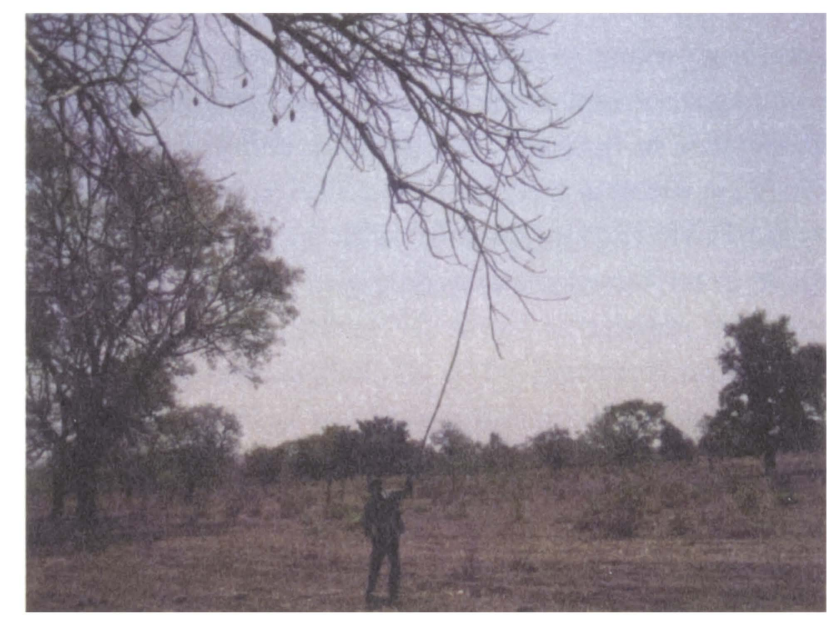

Local harvesting technique for baobab fruits in Benin. 
Harvesting of baobab and tamarind fruits, and baobab leaves is highly seasonal. This is further reflected in the commercialisation of baobab and tamarind products which is found to occur chiefly during the dry season in Benin. In Mali, marketing of baobab and tamarind products is observed to be less seasonal. However, no seasonal storage has been evidenced in Mali and Benin due to a lack of storage infrastructure, space and financial means. Most surveyed chain actors typically purchase a certain volume of produce, which is stored until it is sold, after which they replenish their stock. As a result, storage duration is observed to be very variable. In the present study, dry baobab and tamarind products are mainly stored in recycled rice bags which are kept in the house or in a storehouse or granary, in respectively Benin and Mali. Even though humidity and bug, mice and fungi attacks were reported as main problems during storage, the informants rated overall storage conditions as good.

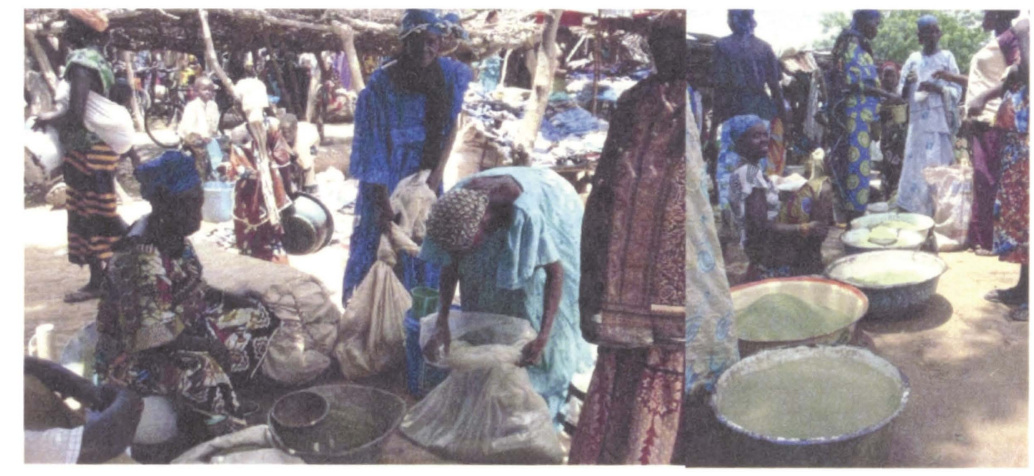

Baobab leaf pouder is sold ungraded.

None of the baobab and tamarind products were reported to be graded or standardised. Direct inspection is the only method reported by which quality is assessed. Moreover, it has been observed that different actors use different quality criteria. All chain actors in Mali and Benin attach great importance to processing and storage techniques for baobab and tamarind products, and expect a well-dried or finely ground product without impurities, which has not been exposed to humidity. Additionally, colour and taste are important quality parameters in Mali, whereas taste is only a criterion in Benin for baobab and tamarind fruits. Maturity, freshness and size, together with the absence of insects or insect lesions are important quality criteria used to assess quality of tamarind fruits and leaves in Mali. The same criteria are used in Benin to assess the quality of fresh baobab leaves.

Lack of market information is recognised by all chain actors as a major constraint in the commercialisation of baobab and tamarind products in Mali and Benin. Information is particularly lacking about harvesting and processing techniques, price, quality and demand. Chain actors in Mali particularly need more information about demand and they reported not to be satisfied with the access to information. In contrast, surveyed actors in Benin especially need information about quality and say to be rather satisfied with the overall information flow. 
Local chain development should build linkages and enhance trust between actors in the market chain. Recommended interventions are formulated in many fields: (i) parallel domestication and commercialisation of baobab and tamarind; (ii) training of smallholders to improve their production and management skills; (iii) supporting smallholders to associate, collaborate and coordinate to achieve economies of scale in their transactions with buyers; (iv) making channels of information and market intelligence accessible to all chain actors; ( $v$ ) enabling chain actors to understand and better satisfy product, process or delivery standards required by buyers; and (vi) improving market institutions. Once the major domestic limitations have been tackled, commercialisation of baobab and tamarind products at regional and international level should be developed and expanded.

In conclusion, most aspects of the market chains of baobab and tamarind products in Mali and Benin studied in the present research have-according to the author's knowledge - not yet been studied and published elsewhere. Therefore, this research should be considered as a pilot case study in obtaining insight in the structure and functioning of the markets of baobab and tamarind products. 